\title{
Estrogen and Morphine Modulate Their Own and the Other's Human Endothelial Receptor Expression via Nitric Oxide
}

\author{
Patrick Cadet ${ }^{1}$, Vincent Prevot ${ }^{2}$, Jean Claude Beauvillain ${ }^{2}$, Thomas V. Bilfinger ${ }^{3}$ and \\ George B. Stefano ${ }^{1}$
}

\author{
${ }^{1}$ Neuroscience Research Institute, State University of New York - College at Old Westbury, Old Westbury, NY 11568, \\ USA \\ ${ }^{2}$ INSERM, U422, IFR 22, Unité de Neuroendocrinologie et Physiopathologie Neuronale, Place de Verdun, 59045 \\ Lille Cedex, France \\ ${ }^{3}$ Division of Cardiothoracic Surgery, Department of Surgery, State University of New York at Stony Brook, Stony \\ Brook, NY \\ *Corresponding Author: \\ Dr. Patrick Cadet
}

Neuroscience Research Institute, State University of New York - College at Old Westbury

Old Westbury, NY 11568, USA

Tel: 516-876-2739; Fax: 516-876-2727

Email: patcad@sunynri.org, Web: www.SUNYNRI.org

Received: 6 November 2008; | Revised: 20 November 2008; | Accepted: 22 November 2008

\begin{abstract}
In previous studies we have demonstrated that $\mu_{3}$ and estrogen $\beta$ receptor subtypes are present in human vascular endothelial cells and coupled to constitutive nitric oxide synthase (cNOS) stimulation. In the present report we demonstrate that internal thoracic artery (ITA) endothelia express a $\mu$ opioid receptor mRNA transcript and exposure of these transcripts to increasing concentrations of $17 \beta$-estradiol significantly diminishes ITA $\mu$ opioid receptor expression. Exposure of ITA endothelia to SNAP, a NO donor, also diminishes $\mu$ opioid receptor gene expression, suggesting that NO mediates, in an L-NAME $\left(\mathrm{N}^{\mathrm{G}}\right.$ nitro-L-arginine methyl ester) and tamoxifen sensitive manner, $17 \beta$-estradiol's down regulating action. ITA endothelia also express an estrogen $\beta$ receptor subtype and, when treated with morphine, in an L-NAME and naloxone sensitive manner diminishes the $\beta$ estrogen receptor's expression. This demonstrates an interactive receptor mediated process via NO for both signaling agents. Additionally, morphine and estrogen actions were examined for their ability to alter adhesion to ITA segments. This treatment resulted in a concentration dependent decrease in monocyte adherence to the vessels at $30 \mathrm{~min}$. Exposure to both agents did not decrease monocyte adherence further. Exposure to L-NAME or either naloxone or tamoxifen, opiate and estrogen cell surface receptor inhibitors, respectively, blocked the decrease in monocyte adherence, demonstrating NO involvement and a specific receptor mediated process. In conclusion, this study demonstrates that an interactive receptor mediated process via NO for both signaling agents is present.
\end{abstract}

Keywords: $17-\beta$-estradiol; tamoxifen; morphine; estrogen receptor; mu opiate receptor 


\subsection{Introduction}

In previous studies we demonstrated that $\mu_{3}$ and estrogen $\beta$ receptor subtype are present in human vascular endothelial cells[1-3]. In regard to estrogen, we tested the hypothesis that estrogen acutely stimulates constitutive nitric oxide synthase (cNOS) activity in human endothelial cells by acting on a membrane surface receptor [2]. 17 $\beta$-estradiol exposure to internal thoracic artery (ITA) endothelia and arterial endothelia in culture stimulated NO release within seconds in a concentration-dependent manner whereas $17 \alpha$ estradiol had no effect. 17 $\beta$-estradiol conjugated to bovine serum albumin ( $\mathrm{E}_{2}$-BSA) also stimulated NO release, suggesting mediation by a membrane surface receptor. Tamoxifen, an estrogen receptor inhibitor, antagonized the action of both $17 \beta$ estradiol and $\mathrm{E}_{2}$-BSA [2]. We further showed using a dual emission microfluorometry method in a calcium free medium that the $17 \beta$-estradiol stimulated release of endothelial NO was dependent on the initial stimulation of intracellular calcium transients. Furthermore, RT-PCR analysis of RNA obtained from the endothelial culture revealed only a estrogen receptor- $\beta$ amplification signal [2].

Furthermore, in regard to opioid receptor subtypes, a $\mu_{3}$ opiate receptor, one that is opioid peptide insensitive and opiate alkaloid selective, appears to be present on human vascular endothelia $[4,5]$. Pharmacologic and immunologic evidence suggests that NO-coupled $\mu$-subtype opiate receptors are expressed in human vascular endothelium [4,6-13]. Using primers derived from the human neuronal $\mu 1$ opiate receptor, we used RT-PCR to detect expression of $\mu$ transcripts from human endothelia [4]. Sequence analysis of the RT-PCR products revealed $100 \%$ identity with the neuronal human $\mu 1$ receptor. We further show that pretreatment of human ITA and cardiac atrial endothelium with the proinflammatory cytokines interleukin-1- $\alpha$ and $-\beta$ led to a significant increase in both the expression of the $\mu$ transcript and in morphine-stimulated NO release. Taken together, these studies provide molecular evidence that $\mu$ type opiate receptors are expressed in human vascular endothelia and that their expression can be up regulated by proinflammatory cytokines and down regulated by morphine via NO [4,5].

Given the above, especially the similarity of morphine and estrogen (endogenous signaling molecules) in stimulating cNOS -derived NO release we sought to determine if these signaling molecules could alter each other's expression. We demonstrate that this indeed occurs, that is morphine and estrogen down regulates each other's receptor expression, demonstrating an interaction between the two signaling systems.

\subsection{Material}

Internal thoracic artery (ITA) segments were obtained from patients undergoing elective coronary artery bypass grafting (CABG) for atherosclerotic coronary artery disease. ITA segments were obtained from patients (four postmenopausal women, mean age $74.5 \pm 10.3$ years and eight men mean age $57.6 \pm 13.3$ years. This material is regarded as waste and the institutional review board approved the project. Patients with chronic illnesses, such as diabetes or cancer as well as acute processes (e.g., known infections, trauma), were excluded. In all patients undergoing $\mathrm{CABG}$, the analgesic management included induction with fentanyl (fentanyl citrate adjusted for $\mathrm{pH})$ or sufentanil (N-[4(methoxymethyl0-1-[2-(2 thienyl) ethyl]-4piperidinyl]-N-phenylpropanamide 2 hydroxy$1,2,3$ propanetricaboxylate) up to $15 \mu \mathrm{g} / \mathrm{kg}$. Maintenance was achieved with the same agents. Parts of SV that were not used in the CABG procedure were stored in an electrolyte solution at $4^{\circ} \mathrm{C}$ (500 cc plasmalyte with $5000 \mathrm{U}$ heparin), and these specimens were immediately transported on ice to the laboratory for processing. Immediately upon arrival, each blood vessel was washed in phosphate buffered saline (PBS) and cut into 3$\mathrm{mm}$ rings. ITA specimens were prepared as previously described [14].

\subsection{Treatments}

Tissues were exposed to various concentrations of $17 \beta$-estradiol conjugated to bovine serum albumin ( $\left.\mathrm{E}_{2}-\mathrm{BSA}\right)$ or morphine. To determine that there was no dissociation between $17 \beta$-estradiol and BSA, an RIA kit optimized for the direct quantitative determination of $17 \beta$ - 
estradiol was used (ICN kit, Costa Mesa, CA). $\mathrm{E}_{2}-$ BSA measured in the cytosolic fraction of ITA treated with $10^{-9}$ and $10^{-8} \mathrm{M} \mathrm{E}_{2}$-BSA revealed no estradiol in the cytosol (assay sensitivity was 0.2 $\mathrm{pg} /$ tube). When specific receptor antagonists were employed they were administered 5 min prior to the agonist. Tissues were exposed to the drugs for a total of $30 \mathrm{~min}$. In the case of pure agonist exposure, $5 \mathrm{~min}$ prior to its administration PBS was added in the same volume. Controls consisted of tissues not exposed to drugs. All incubations lasted 18 hours. All drugs were purchased from Sigma Chemical CO. (St. Louis, MO).

\subsection{Isolation of RNA}

Tissue samples, gently scraped of endothelia, were homogenized in Tri-Reagent (Molecular Research Center, INC, Cincinnati, OH) using a polytron homogenizer. The homogenates were stored at room temperature for 5 minutes to allow complete dissociation of nucleoprotein. $0.1 \mathrm{ml}$ of 1-bromo-3-chloropropane (BCP) per $1 \mathrm{ml}$ of TriReagent was added to the homogenates. The samples were vortexed vigorously for 15 seconds and then stored at room temperature for $7 \mathrm{~min}$. After centrifugation of the samples for $15 \mathrm{~min}$ at $12,000 \mathrm{~g}$, the aqueous phase was transferred to a fresh tube. RNA was ethanol precipitated, washed with $75 \%$ ethanol, air-dried and resuspended in water. RNA was analyzed on a $1 \%$ agarose gel and purity determined spectrophotometrically.

\subsection{RT-PCR analysis:}

\subsubsection{Estrogen receptor- $\beta$}

Total RNA from human SV was extracted with Trizol (Gibco/BRL, France) and reverse transcribed into cDNA using random hexamers and Moloney Murine Leukemia Virus RT (Gibco/BRL) [15]. For ER $\beta$ amplification, since it has been previously demonstrated on human endothelial cells [1], the primer pair (25-mers) amplified a $265 \mathrm{bp}$ product (residues 381-469) [16]. As an internal control, glyceraldehyde-3phosphate dehydrogenase (GA3PDH) mRNA was amplified using a primer pair (26-mer) designed to amplify a 470 bp product (residues 36-192) [17]. PCR products were subcloned using a TA cloning vector system (Stratagene, France) and sequenced.

\subsection{2 $\mu$ opiate receptor}

First strand cDNA synthesis was performed using random hexamers (GIBCO, BRL, Gaithesburg, MD). $3 \mu \mathrm{g}$ of total RNA isolated from vascular tissues were denatured at $95{ }^{\circ} \mathrm{C}$ and reverse transcribed at $42{ }^{\circ} \mathrm{C}$ for $1 \mathrm{hr}$ using Superscript II Rnase H-RT (GIBCO BRL, MD). Seven microliters of the RT product was added to the PCR mix containing specific primers for the $\mu$ opioid receptor gene and Taq DNA polymerase (GIBCO, BRL, MD). In order to demonstrate that the PCR was in the linear phase of amplification, various cycles were performed $(15,20,25,30,35$, and 40 cycles, respectively). PCR reactions were denatured at $95{ }^{\circ} \mathrm{C}$ for 5 minutes followed by 30 cycles at $95{ }^{\circ} \mathrm{C}$ for $1 \mathrm{~min}, 57^{\circ} \mathrm{C}$ for $1 \mathrm{~min}$, and 72 ${ }^{\circ} \mathrm{C}$ for $1 \mathrm{~min}$, and then an extension step cycle at $72{ }^{\circ} \mathrm{C}$ for $10 \mathrm{~min}$. PCR products were analyzed on a $2 \%$ agarose gel (Sigma) and visualized by ethidium bromide staining. The only $\mu$-specific primers used in the PCR reactions that yielded a specific PCR product amplified a $441 \mathrm{bp}$ fragment starting at map position 896 (Primer M1 5'GGTACTGGGAAAACCTGCTGAAGATCTG TG3'), and at map position 1336 (primer M4 5'GGTCTCTAGTGTTCTGACGAATTCGAGTG G3'). This segment of the gene encodes the third extracellular loop of the receptor that is important for $\mu$ agonist selectivity. The bands corresponding to the expected size fragment were excised, purified with the StrataPrep purification kit (Stratagene), ligated into the PCR-Script Amp SK (+) vector (Stratagene) and transformed into XL10-Gold kan competent cells (Stratagene). Primers specific for the internal control gene (G3PDH) were used to amplify a $451 \mathrm{bp}$ fragment. Five $\mu l$ of the RT products were used in the PCR reaction followed by 25 cycles at $95{ }^{\circ} \mathrm{C}$ for $1 \mathrm{~min}$, $60{ }^{\circ} \mathrm{C}$ for $1 \mathrm{~min}$, and $72{ }^{\circ} \mathrm{C}$ for $1 \mathrm{~min}$, and then an extension step cycle at $72{ }^{\circ} \mathrm{C}$ for $10 \mathrm{~min}$.

Band density readings were determined by Gel Pro Density Analysis (Media Cybemetrics, Inc., MD). The readings were determined both without and after exposure to interleukins (IL) as indicated in the text. Pharmacological agents were purchased from Sigma (St. Louis, MO). Bands corresponding to the expected size fragment were purified and sequenced with the ABI Prism 
BigDye Terminator Cycle Sequencing Ready Reaction Kit (PE Applied Biosystems-PerkinElmer) and the ABI Prisms 310 Genetic Analyzer and ABI 377 DNA sequencer.

\subsection{Immunocyte adherence}

Human monocytes, used for the study of their adherence to the vascular ITA surface, were obtained from Long Island Blood Services (Melville, Long Island, NY). They were separated by the standard Ficoll-Hypaque method as described elsewhere $[1,18]$. Following separation, the monocytes were washed three times in RPMI medium (RPMI, $25 \mathrm{~m}$ Hepes, Grand Island Biological Co., NY).

Human ITA was obtained from volunteer patients at University Hospital (State University of New York at Stony Brook) who had given their informed consent; these vessels are normally removed during coronary artery bypass grafting (CABG). Patient eligibility included admission for elective $\mathrm{CABG}$ only for atherosclerotic heart disease. Patients with chronic illnesses such as diabetes or cancer as well as acute processes (e.g., known infections, trauma) were not eligible. These patients were not smokers. A total of 5 patients qualified for the present study. In these patients, heparinized blood specimens were obtained prior to induction of anesthesia. In all patients undergoing $\mathrm{CABG}$, the anesthetic management included induction with fentanyl (fentanyl citrate adjusted for $\mathrm{pH}$ ) or sufentanil. Maintenance was achieved with the same agents. It is important to note that fentanyl and sufentanil do not influence the $\mu_{3}$ opiate receptor and thus do not share immunosuppressive actions with morphine (see $[19,20]$ ).

Fluorescence staining was accomplished utilizing a commercially available kit (Sigma, St. Louis, MO). After Ficoll-Hypaque isolation, monocytes, $10^{6} / \mathrm{ml}$, were centrifuged $(8000 \mathrm{rpm}$, $5 \mathrm{~min}$ ) and resuspended in $1.0 \mathrm{ml}$ of diluent containing PKH26-GL (Sigma, St. Louis, Mo.). The cells were then processed according to the manufacturer's instructions. Briefly, cells were incubated in the fluorescent dye solution for 2 min, with gentle mixing; the reaction was stopped by adding plasma $(2 \mathrm{ml})$. The cells were washed in PBS, diluted and divided into $100 \mu \mathrm{l}$ volumes, each containing approximately $416 \pm 17$ cells.

For the studies of monocyte adherence, the ITA sections were carefully cut into $2 \mathrm{~mm}$ rings; the rings were cut longitudinally and placed endothelial side up in $2 \mathrm{ml}$ of PBS. The open rings (edge) were then encircled with a ring of Vaseline. The cells, loaded with the yellowfluorescing dye, were resuspended in $100 \mu \mathrm{l}$ volume (see above, diluted to approximately 400 cells) and added to the endothelial surface. Each viewing diameter was approximately $400 \mu \mathrm{m}$. These experiments were run in parallel to minimize variations due to constitutive nitric oxide release. Additionally, gp120, anti-gp120 and gp120, or anti-gp120 (0.01 to $1 \mathrm{mg} / \mathrm{ml})$ were added to particular preparations prior to cell placement. Other vessels were treated with morphine or $17 \beta$ estradiol with and without their respective antagonists. When antagonists were used, the antagonist was added first; after 5 min the agonist was added. In other preparations, combinations of the different agonists and their respective antagonists were added. Each treatment lasted for 5 minutes. After that, the vessels were washed with PBS. The monocytes were added to the vessels; after 20 minutes the surface of the endothelium was gently washed and the number of adhering monocytes counted. To control for the endothelium, the experiments were repeated in vessels which had been physically denuded (by scraping) of the overlying endothelium.

The vessels and adhering monocytes were visualized by UV microscopy using a Nikon epifluorescent microscope and image analysis. Human monocytes were monitored $30 \mathrm{~min}$ after treatment with the dye. The cells were counted rapidly and automatically using color detection software (American Innovision, San Diego, CA). Briefly, the yellow fluorescing color was selected by the examiner by matching it to 16 million color hues already present in the proprietary capture board. Once the color was identified, the size parameters of the yellow fluorescing cells were set; yellow fluorescing "objects" (debris) with areas below $45 \mu^{2}$ and above $700 \mu \mathrm{m}^{2}$ were ignored. The system then counted the yellow fluorescing cells automatically. Indirect cell 
counting was also employed by noting the number of cells in the incubation medium. Cell viability was determined by trypan blue dye exclusion; $>96 \%$ of the endothelial cells were viable during the course of the experiments.

Results were analyzed using a one-tailed Student's T-test, since each experiment had its own control. Cells were counted by a 'blind' observer.

\subsection{Results}

\subsection{Estrogen down regulates endothelial mu opiate receptor expression.}

ITA express a $\mu$ opioid receptor mRNA transcript (Figure 1 lane 2) [21]. The $\mu$ opioid receptor transcript in control ITA is $441 \mathrm{bp}$. Exposure of these transcripts to increasing concentrations of $17 \beta$-estradiol (Figure 1, Lanes 3,4) significantly diminishes ITA $\mu$ opioid receptor expression. Exposure of ITA endothelia to SNAP, a NO donor, also diminishes $\mu$ opioid receptor gene expression, suggesting that NO mediates $17 \beta$-estradiol's down regulating action (Figure 1, Lane 5). Concomitant exposure of the endothelia to $100 \mathrm{nM} 17 \beta$-estradiol $+1 \mu \mathrm{M} \mathrm{L}$ NAME, a NOS inhibitor, blocks estrogens action, demonstrating that it was exerting its action via cNOS derived NO (Figure 1, Lane 6). Furthermore, $17 \beta$-estradiol's action can be antagonized by concomitant exposure of this tissue to $10 \mathrm{nM} 17 \beta$-estradiol $+10 \mathrm{nM}$ tamoxifen, an estrogen surface antagonist on human endothelia (Figure 2, Lane 3) [2]. In addition, exposure of this tissue to $17 \beta$-estradiol conjugated to bovine serum albumin $\left(\mathrm{E}_{2}-\mathrm{BSA}\right)$ resulted in a $73 \pm 7.4 \%$ reduction in this receptors expression, demonstrating that estrogen itself can diminish its own receptors levels.

\subsection{Estrogen receptor gene expression in human endothelial cells is altered by morphine exposure.}

ITA endothelia express an estrogen $\beta$ receptor subtype [2] (Figure 3, lane 2 top). ITA endothelial cells treated with $10 \mathrm{nM}$ ( Figure 3, lane 3, top) and $100 \mathrm{nM}$ morphine (Figure 3, lane 4, Top) diminish the $\beta$ estrogen receptor's expression (Figure 3, top). Concomitant exposure of these cells to $100 \mathrm{nM}$ morphine plus $100 \mathrm{mM}$ L-NAME
(Figure 3, lane 5) prevents the loss of the estrogen receptors expression. Endothelial cells treated with $100 \mathrm{nM}$ SNAP (Figure 4, lane 3 top) and $100 \mathrm{nM}$ morphine + Naloxone $10^{-7} \mathrm{M}$ (lane 4, Top) diminished and blocked the loss of the $\beta$ estrogen receptors expression, respectively.

\subsection{Immunocyte actions}

The effect of morphine and estrogen on monocyte adherence was studied. For these studies, vessels (ITA segments) were incubated with morphine or $17-\beta$ estradiol $\left(10^{-6} \mathrm{M}\right)$ at different concentrations, washed twice in PBS (2 $\mathrm{X})$ before the monocytes were added. This treatment resulted in a concentration dependent decrease in monocyte adherence to the vessels at 30 min. With morphine or 17- $\beta$ estradiol, the number of adhering cells was $36 \pm 13$ and $39 \pm 10$ at $30 \mathrm{~min}$, respectively, which is significantly lower than for their corresponding controls $158 \pm$ 16 and $166 \pm 18$, respectively. Exposure to both agents did not decrease monocyte adherence further. Exposure to either $\mathrm{N}^{\mathrm{G}}$-nitro-L-arginine methyl ester (L-NAME, $10^{-4} \mathrm{M}$ ), a NOS inhibitor or either naloxone or tamoxifin, opiate and estrogen cell surface receptor inhibitors, respectively, blocked the decrease in monocyte adherence, demonstrating NO involvement and a specific receptor mediated process. Naloxone did not block 17- $\beta$ estradiol action nor did tamoxifin block that of morphine (data not shown).

In vessels exposed to gp120 $(1.0 \mu \mathrm{g} / \mathrm{ml})$ there was an increase in cell adherence (322.4 \pm 21 cells), confirming earlier reports documenting this compounds proinflammatory and vascular activating properties [22-27]. Additionally, exposure to gp120 after exposure of the ITA fragments to morphine or $17-\beta$ estradiol inhibited the gp120-stimulated increase in monocyte adherence. However, at higher doses of gp120 an increase in monocyte adherence again became evident, demonstrating that both morphine's and estrogen's inhibitory actions are reversible, i.e., over come by a stronger stimulus. 


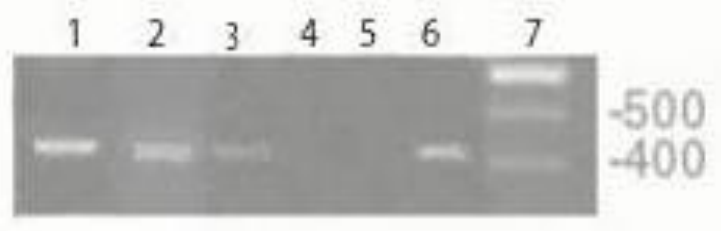

Figure 1. Estrogen down regulates endothelial mu opiate receptor expression. Identification of $\mu$ opioid receptor mRNA transcript. Total RNA isolated from these tissues was reversed transcribed and PCR amplified and run on agarose gels. Lane 1: G3PDH housekeeping gene (expected transcript size is $451 \mathrm{bp}$ ). Lane 2: $\mu$ opioid receptor transcript in healthy saphenous vein endothelia (expected size 441bp). Lane 3: $10 \mathrm{nM} 17 \beta$-estradiol. Lane 4: $100 \mathrm{nM} 17 \beta$ estradiol. Lane 5: 100 nM SNAP. Lane 6: 100 nM $17 \beta$-estradiol + $1 \mu \mathrm{M}$ L-NAME. Lane 7: 100 bp DNA markers. Both negative and positive strands were sequenced, however, only the sequence from the negative strand is shown in lane 2. The tissues were washed extensively with PBS to limit any contamination.

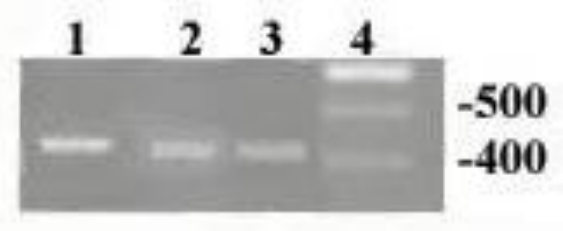

Figure 2. Estrogen down regulates endothelial mu opiate receptor expression. Identification of $\mu$ opioid receptor mRNA transcript. Total RNA isolated from these tissues was reverse transcribed and PCR amplified and run on agarose gels. Lane 1: G3PDH housekeeping gene (expected transcript size is 451 bp). Lane 2: $\mu$ opioid receptor transcript in healthy saphenous vein endothelia (expected size 441bp). Lane 3: $10 \mathrm{nM} 17 \beta$ estradiol + $10 \mathrm{nM}$ tamoxifen. Lane 4: $100 \mathrm{bp}$ DNA markers. Both negative and positive strands were sequenced, however, only the sequence from the negative strand is shown in lane 2. The tissues were washed extensively with PBS to limit any contamination.

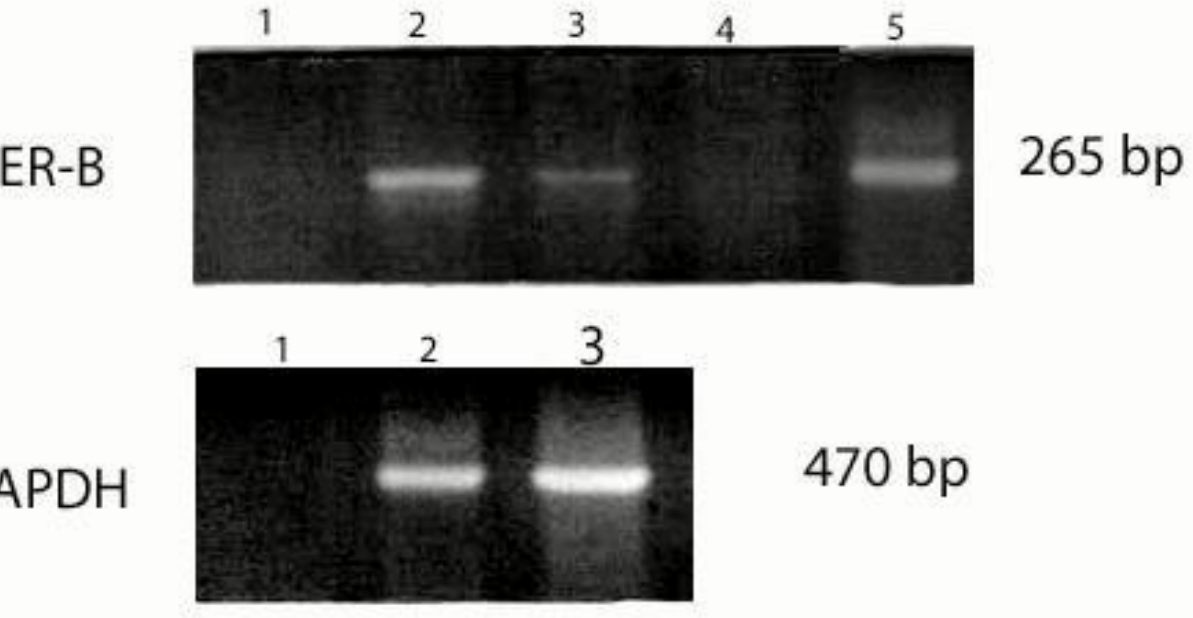

Figure 3. Estrogen receptor gene expression in human endothelial cells is altered by morphine exposure. RTPCR was performed using either no RNA (Top and Bottom, negative control, lane 1) or $3 \mu \mathrm{g}$ of RNA from human endothelial cells (positive control, lane 2, Top), endothelial cells treated with $10 \mathrm{nM}$ morphine (lane 3) and $100 \mathrm{nM}$ morphine (lane 4, Top). $100 \mathrm{nM}$ morphine plus $100 \mathrm{mM}$ L-NAME (lane 5). PCR amplification was also performed using a primer pair specific for human GAPDH as a cDNA control 
(Bottom). The PCR products (one fifth of the ER $\beta$ reaction, one tenth for GAPDH amplification) were separated electrophoresis on a $2 \%$ agarose gel. DNA markers $(1 \mathrm{~Kb}$ ladder) were run in parallel. The sizes of the amplified products are indicated in the base pair on the right.

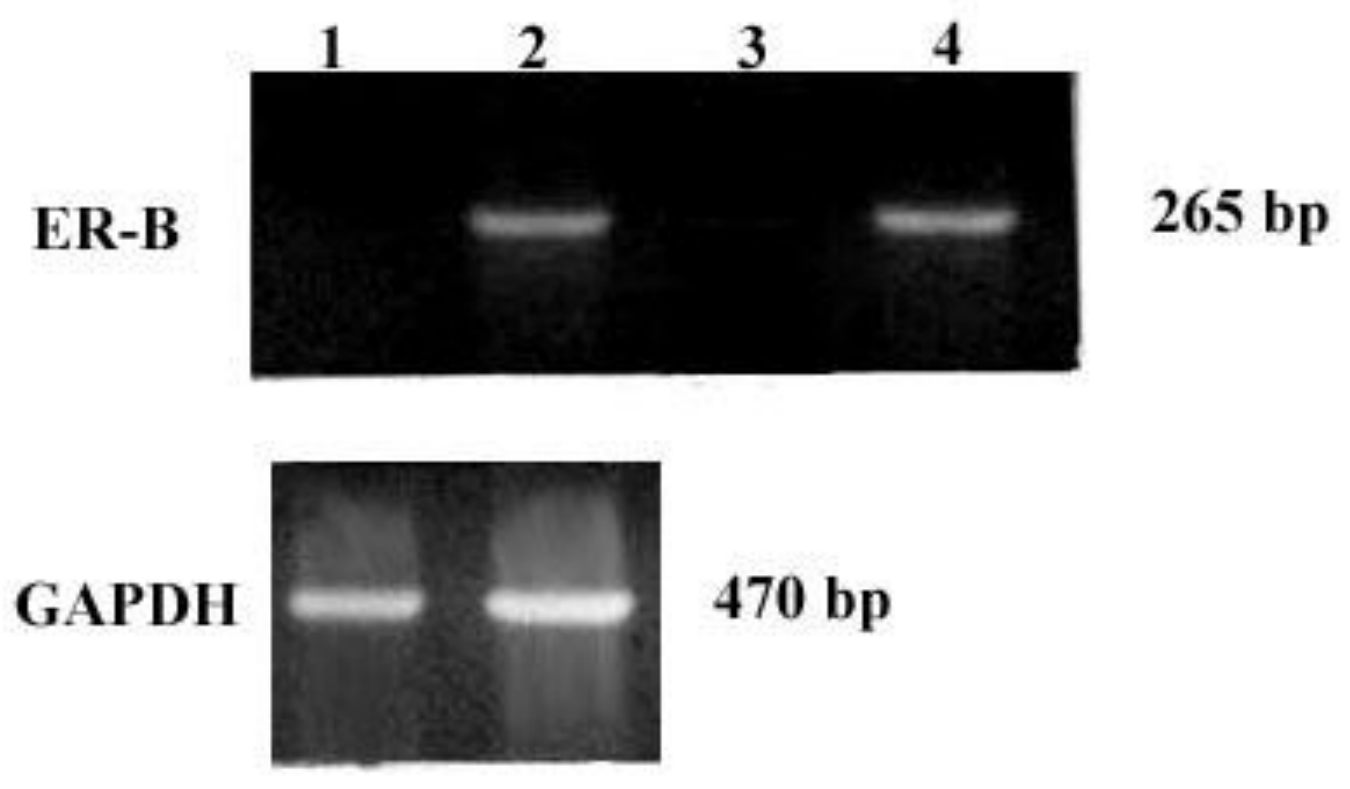

Figure 4. Estrogen receptor gene expression in human endothelial cells is altered by morphine exposure. RTPCR was performed using either no RNA (Top and Bottom, negative control, lane 1) or $3 \mu \mathrm{g}$ of RNA from human endothelial cells (positive control, lane 2, Top), endothelial cells treated with 100 nM SNAP (lane 3) and $100 \mathrm{nM}$ morphine + Naloxone $10^{-7} \mathrm{M}$ (lane 4, Top). PCR amplification was also performed using a primer pair specific for human GAPDH as a cDNA control (Bottom). The PCR products (one fifth of the ER $\beta$ reaction, one tenth for GAPDH amplification) were separated electrophoresis on a $2 \%$ agarose gel. DNA markers ( $1 \mathrm{~Kb}$ ladder) were run in parallel. The size of the amplified products is indicated in the base pair on the right.

\subsection{Discussion}

The present study demonstrates the following: 1) Morphine can down regulate the estrogen $\beta$ receptor subtype in ITA endothelia in a naloxone antagonizable manner; 2) SNAP, a nitric oxide donor, also can down regulate the estrogen $\beta$ receptor subtype's expression in ITA endothelia; 3) Morphine exerts its down regulation of the estrogen $\beta$ receptor subtype by liberating cNOS derived NO as determined by L-NAME blockade; 4) 17- $\beta$ estradiol can down regulate $\mu$ opioid receptor expression in ITA endothelia in a tamoxifin antagonizable manner; 5) SNAP also can down regulate the $\mu$ opioid receptor subtype's expression in ITA endothelia; 6) 17- $\beta$ estradiol exerts its down regulation of the $\mu$ opioid receptor subtype expression by liberating cNOS derived NO as determined by L-NAME blockade; and lastly, 7) Estrogen can down regulate the expression of it's cell surface receptor in ITA. Taken together, both signal systems respond to specific and appropriate agonist activity by liberating NO, which then down regulates their 
receptors, respectively. It would appear that cNOS derived NO modulates the expression of both receptors, insuring that cNOS derived NO following large pulses, cannot continue indefinitely.

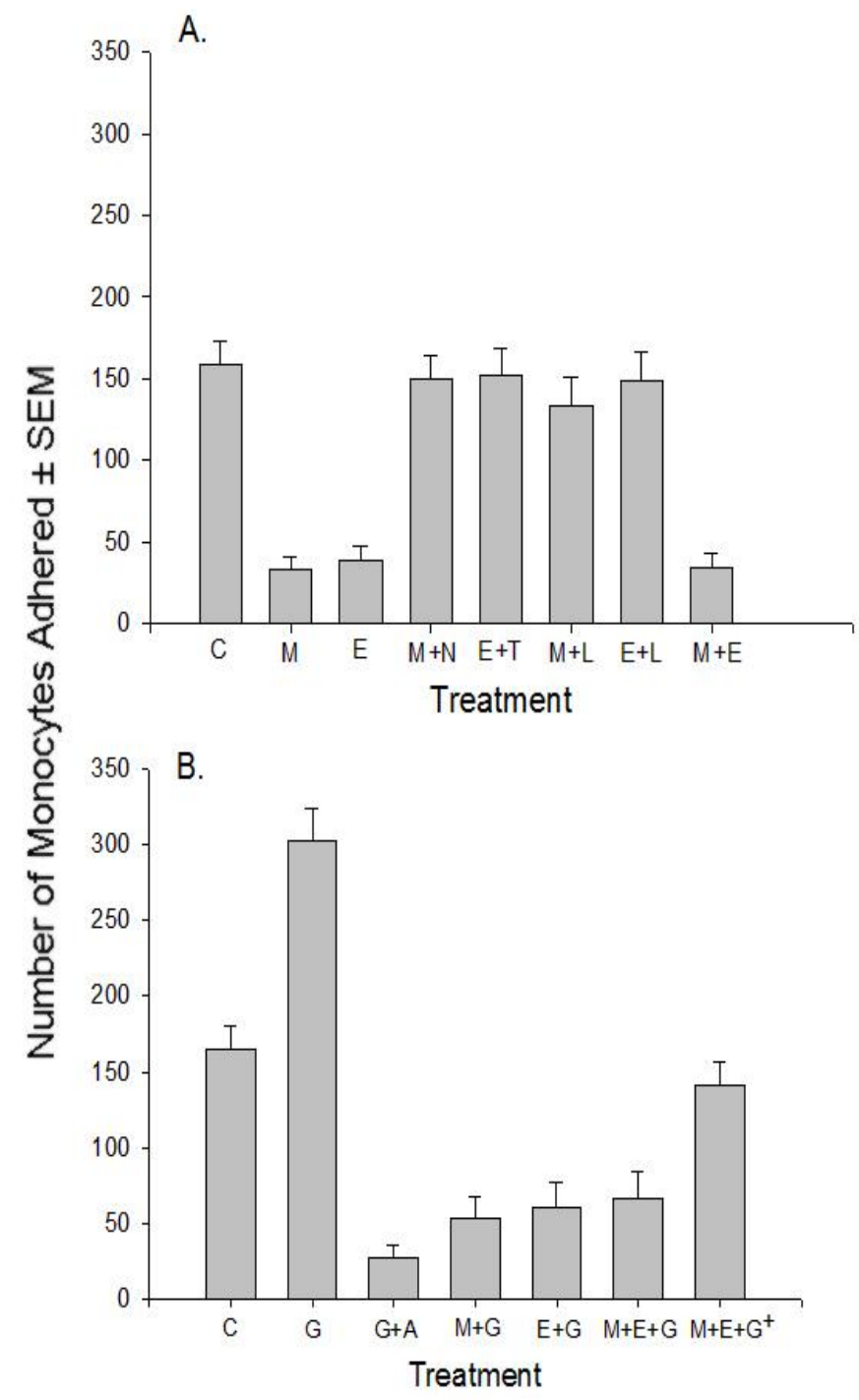

Figure 5. The effect of Morphine and estrogen on human monocyte adherence to ITA endothelia surface.

A. Control preparations adhere monocytes, a process that is significantly diminished by morphine $\left(\mathrm{M} ; 10^{-7} \mathrm{M}\right)$ and $17 \beta$ estradiol $\left(\mathrm{E} ; 10^{-9}\right.$ $\mathrm{M})$ and blocked by naloxone $\left(\mathrm{N} ; 10^{-7} \mathrm{M}\right)$ and tamoxifin $\left(\mathrm{T} ; 10^{-9} \mathrm{M}\right)$, opiate and estrogen receptor antagonists, respectively, as well as by the constitutive nitric oxide synthase inhibitor L-
NAME $\left(\mathrm{L} ; 10^{-4} \mathrm{M}\right)$. Morphine and estrogen do not reduce monocyte adherence beyond the level achieved by each ligand administered alone, indicating that the maximal effect is achieved by simply stimulating cNOS derived NO. Each experiment was repeated five times and significance between control and morphine or estrogen treated endothelial surface is at the $95 \%$ level of confidence as also is the case for antagonist and L-NAME comparisons to either M or $\mathrm{E}$ alone.

B. The effect of $\mathrm{M}$ or $\mathrm{E}$ on gp120 stimulated monocyte adherence to human ITA endothelia surface. Gp120 (G; $100 \mathrm{ng} / \mathrm{ml}$ ) significantly enhanced monocyte adherence in an anti-gp120 (A; $100 \mathrm{ng} / \mathrm{ml}$ ) manner. Furthermore, pretreatment of the vessel with either morphine $\left(\mathrm{M} ; 10^{-7} \mathrm{M}\right)$ or $17 \beta$-estradiol $\left(\mathrm{E} ; 10^{-9} \mathrm{M}\right)$ or both also blocked the $\mathrm{G}$ induced increase in adherence.

In previous reports from our group we have demonstrated that morphine liberates cNOS derived NO from vascular endothelial cells [5$7,14,19,26,28,29]$. This naloxone antagonizable action of morphine is mediated by a $\mu$ opioid receptor found on this tissue [12], which appears to be a $\mu$ splice variant [4]. This $\mu$ receptor subtype can also be up regulated by proinflammatory cytokines and down regulated by morphine [4]. Furthermore, these same cells contain a cell surface estrogen receptor subtype, namely $\beta$, that is also coupled to cNOS derived NO release [2], suggesting an interaction between these signaling processes since cNOS derived NO represents a common end point.

In the literature there is a small body of work that demonstrates that estrogen influences $\mu$ opioid receptor expression [30]. The binding of $[3 \mathrm{H}]$-diprenorphine in human neuroblastoma cells transfected with an estrogen receptor cDNA (SKER3 cell line) and then exposed to17 $\beta$-estradiol revealed that the number of opioid receptors is reduced at 6 days [31]. In another study, laserscanning microscopy demonstrated that estrogen treatment induces the translocation of mu-OR immunoreactivity (mu-ORi) from the membrane to an internal location in steroid-sensitive cell 
groups of the limbic system and hypothalamus [32].

On the contrary, others have found an increase in $\mu$ opioid receptor expression. Estrogen treatment alters $\mu$-opioid receptor mRNA levels in different areas of the forebrain of ovariectomized female [33]. They found an increase in mu-opioid receptor mRNA levels in the ventromedial nucleus of the hypothalamus and arcuate nucleus after $48 \mathrm{~h}$ of $10 \mathrm{mg}$ of $17-\beta$-estradiol-3-benzoate treatment when compared to ovariectomized females. No effects of estrogen were observed on mu-opioid receptor mRNA levels in the posterior medial nucleus of the amygdala, hippocampus, caudateputamen or the medial habenula [33]. Exposure of ovariectomized rats to estradiol for $48 \mathrm{~h}$ increased the density of $[3 \mathrm{H}]$ naloxone binding in both the ventral and dorsal premammillary nuclei but not in other regions of the hypothalamus or amygdale [34]. These contradictions may also be due to the lack of opiate alkaloid use, that is $\mu$ opioid peptides were employed and they don't release NO see $[7,9,12,19]$. Additionally, the various binding ligands employed can also react with other opioid receptor subtypes, i.e., $\delta$.

Given the interaction demonstrated in the current study we offer the following speculation. At first glance, it may appear that we have a redundant immunovascular down regulating process. However, we believe that each signaling system performs this common function, i.e., cNOS derived NO release, under different circumstances. Morphine, given its long latency before increases in its levels are detected, arises after trauma/inflammation to down regulate these processes in neural and immune tissues $[7,35,36]$. Anandamide, by being part of the always present

\section{References}

1. Stefano, G. B.; Prevot, V.; Beauvillain, J. C.; Fimiani, C.; Welters, I. D.; Cadet, P.; Breton, C.; Pestel, J.; Salzet, M.; Bilfinger, T. V. Estradiol coupling to human monocyte nitric oxide release is dependent on intracellular calcium transients: Evidence for an estrogen surface receptor, J.Immunol., 1999, 16337583763.

2. Stefano, G. B.; Prevot, V.; Beauvillain, J. C.; arachidonate and eicosanoid signaling processes serve to maintain tonal $\mathrm{NO}$ in vascular tissues [37]. We surmise that estrogen, since testosterone or progesterone don't exert this NO generating action, provides an extra-degree of immunocyte and vascular down regulation in females. This is most probably due to both the immune and vascular trauma associated with cyclic reproduction activities, i.e., endometrial buildup, when a high degree of vascular and immune activities are occurring. Given the high degree of proliferative growth capacity during estrogen peak levels in this cycle, NO may function to enhance down regulation of the immune system to allow for these changes. In this regard, it is not difficult to understand the reports documenting various cancers with blocking estrogen actions and conversely reports documenting its anti-cancer protective actions [38].

Thus, since both estrogen and morphine via NO down regulate each other's receptor expression, we surmise that this phenomenon is involved with the tissues ability to down regulate it's excitation to a level that does not compromise the tissues ability to respond to additional excitation. If one signal molecule down regulates the tissue's excitation potential the other signal molecule would down regulate it further. However, this is not the case, since the others receptor is down regulated as well. This allows the tissue to recover or become excited if called upon. Furthermore, it would allow for a stronger excitatory response since an additive effect on down regulating influences would not be felt, regardless of whether or not they are expressed.

Bilfinger, T. V.; Fimiani, C.; Welters, I.; Fricchione, G. L. Acute exposure of estrogen to human endothelia results in nitric oxide release mediated by an estrogen surface receptor coupled to intracellular calcium transients, Circulation, 2000, 1011594-1597.

3. Stefano, G. B.; Cadet, P.; Breton, C.; Goumon, Y.; Prevot, V.; Dessaint, J. P.; Beauvillain, J. C.; Roumier, A. S.; Salzet, M. Estradiol-stimulated nitric oxide release in human granulocytes is dependent on 
intracellular calcium transients: Evidence for a cell surface estrogen receptor, Blood, 2000, 95(12), 3951-3958.

4. Cadet, P.; Bilfinger, T. V.; Fimiani, C.; Peter, D.; Stefano, G. B. Human vascular and cardiac endothelia express mu opiate receptor transcripts, Endothelium, 2000, 7185-191.

5. Cadet, P.; Mantione, K. J.; Stefano, G. B. Molecular identification and functional expression of mu3, a novel alternatively spliced variant of the human mu opiate receptor gene, Journal of Immunology, 2003, 170(10), 5118-5123.

6. Stefano, G. B.; Hartman, A.; Bilfinger, T. V.; Magazine, H. I.; Liu, Y.; Casares, F.; Goligorsky, M. S. Presence of the mu3 opiate receptor in endothelial cells: Coupling to nitric oxide production and vasodilation, J.Biol.Chem., 1995, 270(51), 30290-30293.

7. Stefano, G. B. Autoimmunovascular regulation: Morphine and anandamide stimulated nitric oxide release, Journal of Neuroimmunology, 1998, 8370-76.

8. Stefano, G. B. The $\mu 3$ opiate receptor subtype, Pain Forum, 1999, 8206-209.

9. Bilfinger, T. V.; Stefano, G. B. Human aortocoronary grafts and nitric oxide release: Relationship to pulsatile pressure, Annals of Thoracic Surgery, 2000, 69480-485.

10. Bilfinger, T. V.; Vosswinkel, J. A.; Rialas, C.; Krukenkamp, I. B.; Stefano, G. B. Functional assessment of disease free saphenous vein grafts at redo coronary artery bypass grafting, Ann.Thorac.Surg., 2000, 69(4), 1183-1187.

11. Stefano, G. B.; Goumon, Y.; Bilfinger, T. V.; Welters, I.; Cadet, P. Basal nitric oxide limits immune, nervous and cardiovascular excitation: Human endothelia express a mu opiate receptor, Progress in Neurobiology, 2000, 60513-530.

12. Stefano, G. B.; Goumon, Y.; Casares, F.; Cadet, P.; Fricchione, G. L.; Rialas, C.; Peter, D.; Sonetti, D.; Guarna, M.; Welters, I.; Bianchi, E. Endogenous morphine, Trends in Neurosciences, 2000, 9436-442.

13. Welters, I. D.; Menzebach, A.; Goumon, Y.; Cadet, P.; Menges, T.; Hughes, T. K.; Hempelmann, G.; Stefano, G. B. Morphine inhibits $\mathrm{NF}-\kappa \mathrm{B}$ nuclear binding in human neutrophils and monocytes by a nitric oxide dependent mechanism., Anesthesiol., 2000, 92(6), 1677-1684.

14. Bilfinger, T. V.; Hartman, A.; Liu, Y.; Magazine, H. I.; Stefano, G. B. Cryopreserved veins used for myocardial revascularization: A 5 year experience and a possible mechanism for their increased failure, Ann.Thorac.Surg., 1997, 631063-1069.

15. Breton, C.; Pechoux, C.; Morel, G.; Zingg, H. H. Oxytocin receptor messenger ribonucleic acid: characterization, regulation, and cellular localization in the rat pituitary gland, Endocrinology, 1995, 1362928-2932.

16. Mosselman, S.; Polman, J.; Dijkema, R. ER beta: identification and characterization of a novel human estrogen receptor, FEBS Lett., 1996, 39249-53.

17. Allen, R. W.; Trach, K. A.; Hoch, J. A. Identification of the $37-\mathrm{kDa}$ protein displaying a variable interaction with the erythoid cell membrane as glyceraldehyde-3-phosphate dehydrogenase, J.Biol.Chem., 1987, 262649653.

18. Stefano, G. B.; Digenis, A.; Spector, S.; Leung, M. K.; Bilfinger, T. V.; Makman, M. H.; Scharrer, B.; Abumrad, N. N. Opiate-like substances in an invertebrate, an opiate receptor on invertebrate and human immunocytes, and a role in immunosuppression, Proc.Natl.Acad.Sci.USA, 1993, 9011099-11103.

19. Stefano, G. B.; Scharrer, B.; Smith, E. M.; Hughes, T. K.; Magazine, H. I.; Bilfinger, T. V.; Hartman, A.; Fricchione, G. L.; Liu, Y.; Makman, M. H. Opioid and opiate immunoregulatory processes, Crit.Rev.in Immunol., 1996, 16(2), 109-144.

20. Stefano, G. B. Fentanyl does not exhibit naloxone sensitive immune and vascular regulatory actions, Curr.Opin.Clinical Exper.Res., 2000, 2(3), 117-129.

21. Stefano, G. B.; Weeks, B. S.; Cadet, P. GP120 promotes HIV survival by distracting immune surveillance, Modern Aspects of Immunobiology, 2000, 1(2), 63-68.

22. Stefano, G. B.; Smith, E. M.; Cadet, P.; Hughes, T. K. HIV GP120 alteration of DAMA and IL-1a induced chemotaxic responses in human and invertebrate 
immunocytes, J.Neuroimmunol., 1993, 43177184.

23. Stefano, G. B.; Smith, E. M.; Paemen, L. R.; Hughes, T. K. HIV GP120 associated neurological deficits: A potential role for nitric oxide and other signal molecules, Adv.Neuroimmunol., 1993, 3(1), 47-57.

24. Brenneman, D. E.; McCune, S. K.; Mervis, R. F.; Hill, J. M. Gp120 as an etiologic agent for neuroAIDS: Neurotoxicity and model systems, Adv.Neuroimmunol., 1994, 4157-166.

25. Gendelman, H. E.; Genis, P.; Jett, M.; Zhai, Q.-H.; Nottet, L. M. An experimental model system for HIV-1-induced brain injury, Adv.Neuroimmunol., 1994, 4189-194.

26. Stefano, G. B.; Salzet, M.; Bilfinger, T. V. Long-term exposure of human blood vessels to HIV gp120, morphine and anandamide increases endothelial adhesion of monocytes: Uncoupling of Nitric Oxide, J.Cardiovasc.Pharmacol, 1998, 31862-868.

27. Stefano, G. B.; Salzet, M.; Rialas, C.; Mattocks, D. W.; Fimiani, C.; Bilfinger, T. V. Macrophage behavior associated with acute and chronic exposure to HIV GP120, morphine and anandamide: Endothelial implications, Int.J.Cardiol., 1998, 64(1), S3S13.

28. Magazine, H. I.; Liu, Y.; Bilfinger, T. V.; Fricchione, G. L.; Stefano, G. B. Morphineinduced conformational changes in human monocytes,granulocytes, and endothelial cells and in invertebrate immunocytes and microglia are mediated by nitric oxide, J.Immunol., 1996, 1564845-4850.

29. Cadet, P.; Mantione, K. J.; Zhu, W.; Kream, R. M.; Sheehan, M.; Stefano, G. B. A functionally coupled mu3-like opiate receptor/nitric oxide regulatory pathway in human multi-lineage progenitor cells, Journal of Immunology, 2007, 179(9), 5839-5844.

30. Joshi, D.; Billiar, R. B.; Miller, M. M. Modulation of hypothalamic mu-opioid receptor density by estrogen: a quantitative autoradiographic study of the female C57BL/6J mouse, Brain Res.Bull., 1993,
30629-630.

31. Maggi, R.; Ma, Z. Q.; Pimpinelli, F.; Maggi, A.; Martini, L. Decrease of the number of opioid receptors and of the responsiveness to morphineduring neuronal differentiation induced by 17beta-estradiol in estrogen receptor-transfected neuroblastoma cells (SKER3), Neuroendocrinology, 1999, 69(1), 5462.

32. Eckersell, C. B.; Popper, P.; Micevych, P. E. Estrogen-induced alteration of mu-opioid receptor immunoreactivity in the medial preoptic nucleus and medial amygdala, Journal of Neuroscience, 1998, 18(10), 39673976.

33. Quinones-Jenab, V.; Jenab, S.; Ogawa, S.; Inturrisi, C.; Pfaff, D. W. Estrogen regulation of mu-opioid receptor mRNA in the forebrain of female rats, Brain Research, 1997, Molecular Brain Research. 47(1-2), 134-138.

34. Brown, L. L.; Pasi, S.; Etgen, A. M. Estrogen regulation of $\mathrm{mu}$ opioid receptor density in hypothalamic premammillary nuclei, Brain Research, 1996, 742(1-2), 347351.

35. Stefano, G. B.; Scharrer, B. Endogenous morphine and related opiates, a new class of chemical messengers, Adv.Neuroimmunol., 1994, 457-68.

36. Brix-Christensen, V.; Tonnesen, E.; Sorensen, I. J.; Bilfinger, T. V.; Sanchez, R. G.; Stefano, G. B. Effects of anesthesia based on high versus low doses of opiate on the cytokine and acute phase protein responses in patients undergoing cardiac surgery, Acta Anaesthesiol.Scand., 1998, 4263-70.

37. Fimiani, C.; Liberty, T.; Aquirre, A. J.; Amin, I.; Ali, N.; Stefano, G. B. Opiate, cannabinoid, and eicosanoid signaling converges on common intracellular pathways: nitric oxide coupling, Prostaglandins, 1999, 57(1), 23-34.

38. Service, R. F. New role for estrogen in cancer?, Science, 1998, 280987-988. 